\title{
Adaptação da Escala Expectativas Acadêmicas de Estudantes Ingressantes na Educação Superior
}

\author{
Claisy Maria Marinho-Araujo ${ }^{1}$, Denise de Souza Fleith \\ Universidade de Brasília, Brasília-DF, Brasil \\ Leandro Silva Almeida \\ Universidade do Minho, Braga, Portugal \\ Cynthia Bisinoto, Mauro Luiz Rabelo \\ Universidade de Brasília, Brasília-DF, Brasil
}

\section{RESUMO}

O objetivo deste estudo foi adaptar e validar, para o contexto brasileiro, uma escala portuguesa sobre expectativas acadêmicas de estudantes que ingressam no Ensino Superior, identificando fatores relacionados à participação e ao envolvimento acadêmico dos discentes. Participaram 339 estudantes universitários. Da versão brasileira do instrumento constaram 62 itens respondidos em uma escala de seis pontos que varia de "discordo totalmente" a "concordo totalmente". A análise fatorial gerou sete fatores: Formação Acadêmica de Qualidade, Compromisso Social e Acadêmico, Ampliação das Relações Interpessoais, Oportunidade de Internacionalização e Intercâmbio, Perspectiva de Sucesso Profissional, Preocupação com Autoimagem e Desenvolvimento de Competências Transversais. Os índices alfa de fidedignidade variaram de 0,71 a 0,90 . Os resultados indicam que a escala é uma ferramenta útil de avaliação das expectativas de ingressantes, podendo fornecer subsídios às instituições de educação superior na revisão de propostas pedagógicas de cursos, bem como na elaboração de programas e serviços de apoio aos estudantes.

Palavras-chave: expectativas; educação superior; estudante; adaptação de escala.

\section{ABSTRACT - Adaptation of the Academic Expectation Scale of Freshman University Students}

The purpose of this study was to adapt and to obtain evidence of validity of a Portuguese scale of academic expectations of freshmen university students, for the Brazilian context, identifying factors associated with students' academic participation and involvement. Three hundred and thirty-nine university students participated in the research. The Brazilian version of the instrument consisted of 62 items to be answered in a 6-point scale varying from totally disagree to totally agree. The factor analysis generated seven factors: Academic Training of Quality, Social and Academic Commitment, Extension of Interpersonal Relationships, Opportunity for Students' Interchanges and Internationalization, Professional Success and Perspectives, Self-image Concerns, and Development of Transversal Competencies. The alpha reliability indices ranged from .71 to .90 . The results indicated that the scale is useful for evaluating expectations of 1st year students, and may subsidize higher education institutions concerning the review of pedagogical curricula of undergraduate courses, the development of programs and support services for students.

Keywords: expectations; higher education; student; scale adaptation.

RESUMEN - Adaptación de la Escala Expectativas Académicas para Estudiantes que Ingresan en la Universidad El objetivo de este estudio fue adaptar y validar, en el contexto brasileño, una escala portuguesa sobre expectativas académicas de estudiantes que ingresan en la universidad, identificando factores relacionados con su participación y compromiso académico. Participaron 339 estudiantes. La versión brasileña del instrumento constaba de 62 ítems respondidos en una escala de seis puntos que iba desde muy en desacuerdo a totalmente de acuerdo. El análisis factorial generó siete factores: Formación Académica de Calidad, Compromiso Social y Académico, Ampliación de las Relaciones Interpersonales, Oportunidad de Internacionalización e Intercambio, Perspectiva de Éxito Profesional, Preocupación de la Propia Imagen y Desenvolvimiento de Competencias Transversales. Los índices alfa de fiabilidad oscilaron de 0,71 a 0,90 . Los resultados indican que la escala es una herramienta útil de evaluación de las expectativas de nuevos alumnos, pudiendo conceder subvenciones a las universidades en la revisión de propuestas de cursos, así como una elaboración de programas y servicios al estudiante.

Palabras clave: expectativas; educación superior; estudiante; adaptación del escala.

O Ensino Superior desempenha papel de destaque na construção e divulgação da produção cultural, em prol do bem-estar social. Historicamente, essa modalidade é compreendida como instituição produtora 
de conhecimento e compromissada com a formação de sujeitos conscientes de seu papel na transformação da sociedade em que vivem. Especialmente a partir da década de 1990, novas configurações econômicas e culturais, aliadas aos avanços científicos e tecnológicos, impactaram a organização social e do mundo trabalho em escala mundial, com consequências para o Ensino Superior (Almeida, Marinho-Araujo, Amaral, \& Dias, 2012; Dias Sobrinho, 2010; Dourado 2011; Lima, 2013).

No Brasil, o sistema ampliou-se velozmente na última década, ocasionando mudanças institucionais no âmbito político-pedagógico e acadêmico, bem como no perfil dos estudantes. Em 2013, o país atingiu um total de 7.305.977 alunos matriculados em cursos presenciais e a distância; dessas matrículas, 1.932 .527 são em instituições de ensino públicas, e 5.373 .450 em instituições privadas. Das atuais 2.391 Instituições de Educação Superior (IES), 2.090 são privadas (87\%) e 301 públicas (13\%), ofertando ao todo 32.049 cursos de graduação (Instituto Nacional de Estudos e Pesquisas Educacionais Anísio Teixeira [INEP], 2014). Essa atual conjuntura de expansão e massificação favoreceu a entrada de estudantes oriundos de camadas socioeconomicamente desfavorecidas e de grupos minoritários excluídos historicamente. Tal cenário trouxe para o contexto acadêmico um novo perfil discente, com distintas expectativas e motivações no acesso ao Ensino Superior, que vão sendo confrontadas com a realidade ao longo da trajetória acadêmica (Almeida, Marinho-Araujo, et al., 2012; Dias Sobrinho, 2010, 2013; Vargas \& Paula, 2013).

As expectativas acadêmicas têm papel relevante na transição do Ensino Básico para o Ensino Superior e na permanência desses estudantes no curso na medida em que influenciam a forma como enfrentam os inúmeros e complexos desafios dessa transição e, em especial, como constroem trajetórias acadêmicas bem sucedidas. Entre as múltiplas variáveis que participam do processo de transição, integração e sucesso acadêmico dos discentes, as expectativas que apresentam no momento de ingresso no curso superior mostram-se preditoras da participação acadêmica e, particularmente, do envolvimento nas atividades curriculares (Almeida, Marinho-Araujo, et al., 2012; Araújo et al., 2012; Astin, 1984; Baker \& Schultz, 1992; Kuh, Gonyea, \& Williams, 2005). Funcionam ainda como um filtro por meio do qual os estudantes avaliam e dão sentido à informação e às vivências atuais, levando em consideração tanto suas experiências passadas quanto as perspectivas de futuro (Almeida, Guisande, \& Paisana, 2012; Alves, Gonçalves, \& Almeida, 2012; Costa, Araújo, Gonçalves, \& Almeida, 2013). Estudos sugerem que as expectativas afetam os níveis de compromisso e de investimento dos estudantes com as suas responsabilidades acadêmicas, em particular com as tarefas de aprendizagem associadas ao curso que frequentam. Entretanto, tendo em vista que nem todas as possíveis vivências e dificuldades são antecipadas na ocasião de ingresso na universidade, muitos estudantes, já no primeiro ano do curso superior, tendem a apresentar algum tipo de desilusão com a experiência acadêmica (Almeida, Guisande, et al., 2012; Kuh et al., 2005; Soares et al., 2014). Nesse sentido, as expectativas apresentadas pelos estudantes por ocasião da entrada na universidade parecem constituir um fator relacionado ao processo de integração ao Ensino Superior.

Estudos descritivos, comparativos e correlacionais têm sido realizados com o objetivo de identificar as expectativas apresentadas por estudantes que ingressam no Ensino Superior (Costa et al., 2013; Crisp et al., 2009; Fernandes \& Almeida, 2005; Gil et al., 2013; Gomes \& Soares, 2013; Smith \& Wertlieb, 2005; Soares et al., 2014). Outras investigações têm focado na construção de instrumentos de avaliação das expectativas desse grupo de estudantes. Nos Estados Unidos, o College Student Expectations Questionnaire foi desenvolvido para avaliar as expectativas dos ingressantes na universidade, incluindo seus objetivos, motivações e planos futuros; assim, buscou-se identificar as crenças dos estudantes sobre como seriam suas vivências da universidade e como usariam seu tempo no primeiro ano na instituição (Kuh \& Pace, 1998). Esse instrumento avalia cinco fatores: Atividades Acadêmicas, Conversas (Interações Sociais), Ambiente Universitário, Leitura e Escrita e Opinião sobre a Universidade. Os índices de fidedignidade variam de 0,70 a 0,92 (Gonyea, Kish, Kuh, Muthiah, \& Thomas, 2003). Outro instrumento voltado à identificação das expectativas acadêmicas dos estudantes que estão iniciando o Ensino Superior decorre de um projeto de pesquisa em parceria entre pesquisadores de universidades da Nova Zelândia e Holanda. O Readiness and Expectations Questionnaire avalia as expectativas dos estudantes quanto ao que esperam que aconteça no primeiro ano de curso na universidade e a percepção de preparação para a vida universitária (Jansen, André, \& Suhre, 2013; Jansen \& van der Meer, 2007). A parte desse questionário relativa às expectativas é composta de 32 itens que exploram as dimensões: Indução, Gestão do Tempo, Busca de Ajuda, Independência, Similaridade com o Ensino Médio e Aprendizagem Colaborativa. Os índices de fidedignidade oscilam de 0,60 a 0,80 . A parte do instrumento que diz respeito à prontidão para a vida universitária engloba as dimensões: Gestão do Tempo, Escrita, Habilidade em Tecnologia da Informação e Comunicação, Trabalho em Grupo, Processamento de Informação, Habilidades Verbais e Cultura Universitária. Os índices de fidedignidade variam de 0,60 a 0,83 .

Soares e Almeida (2001) desenvolveram o Questionário de Expectativas Acadêmicas (QEA), o qual tem como objetivo avaliar o que os estudantes esperam realizar ou alcançar ao longo de sua trajetória na universidade. $\mathrm{O}$ instrumento consiste de 38 itens respondidos em uma escala de quatro pontos, que varia de "nunca ou 
quase nunca" a "sempre ou quase sempre", e mede cinco dimensões: Envolvimento Institucional (expectativas quanto à qualidade dos serviços e apoio institucional), Envolvimento Vocacional (expectativas quanto à concretização do plano de carreira), Envolvimento Social (expectativas quanto ao desenvolvimento de relações interpessoais), Utilização de Recursos (expectativas quanto à disponibilidade e utilização de recursos e infraestrutura da universidade) e Envolvimento Curricular (expectativas quanto à formação). Os índices de consistência interna variam de 0,66 a 0,83 .

O Questionário de Percepções Acadêmicas Versão A - Expectativas (QPA-E) (Almeida, Costa, Alves, Gonçalves, \& Araújo, 2012), elaborado por pesquisadores portugueses, tem como objetivo identificar fatores que se mostram preditores da participação acadêmica e do envolvimento dos estudantes nas atividades curriculares. $\mathrm{O}$ instrumento original contem 42 itens respondidos em uma escala de seis pontos, variando de "discordo totalmente" a "concordo totalmente", e distribuídos em sete fatores: (a) Formação para o Emprego e Carreira, referindo-se às expectativas para obtenção de melhores condições de emprego no acesso ao mercado de trabalho (oito itens, como, por exemplo, "ter melhores saídas profissionais no mercado de trabalho"); (b) Desenvolvimento Pessoal e Social, que reflete a valorização do desenvolvimento da autonomia e identidade, autoconfiança e novas experiências de vida (oito itens, como, por exemplo, "ganhar confiança nas minhas potencialidades"); (c) Mobilidade Estudantil, que reflete a orientação do estudante para participar em programas de mobilidade estudantil e intercâmbios e estadias internacionais (oito itens, como, por exemplo, "participar na mobilidade estudantil, passando algum tempo do curso em outro país"); (d) Envolvimento Político e Cidadania, que reflete a motivação do aluno para discutir a vida política, social e econômica do país e contribuir para a melhoria da sociedade, exercendo a sua cidadania ativamente (seis itens, como, por exemplo, "formar-me como um cidadão comprometido com os problemas da sociedade atual"); (e) Pressão Social, que representa a resposta do estudante às expectativas dos outros, nomeadamente da família e grupo de pares, face à sua frequência no ensino superior (quatro itens, como, por exemplo, "conseguir corresponder às expectativas dos meus familiares"); (f) Qualidade da Formação, que representa as expectativas do estudante face às condições proporcionadas no Ensino Superior para um aprofundamento dos seus conhecimentos (quatro itens, como, por exemplo, "aprofundar conhecimentos e matérias na área do meu curso"); e (g) Interação Social, relativamente às expectativas do estudante para ter momentos de convivência e diversão, em atividades de interação social em contexto universitário (quatro itens, como, por exemplo, "ter momentos de convívio e diversão”). Nos estudos envolvendo amostras de estudantes portugueses e espanhóis, realizados até ao momento, obtiveram-se sempre alfas de Cronbach satisfatórios para as dimensões identificadas, oscilando entre $0,78 \mathrm{e}$ 0,93 (Deaño et al., no prelo).

Por entender que as expectativas e experiências vividas pelos estudantes afetam o nível de envolvimento, esforço e efetivo compromisso com o seu próprio processo formativo, desenvolveu-se o presente estudo com o objetivo de adaptar e investigar evidência de validade, baseada na estrutura interna, de uma escala de expectativas acadêmicas de estudantes ingressantes no Ensino Superior brasileiro. Os resultados podem auxiliar na compreensão das dificuldades encontradas pelos estudantes no processo de integração e adaptação a esse nível de ensino e, inclusive, das razões que ocasionam altas taxas de evasão das instituições de Ensino Superior, oferecendo a elas suporte à reformulação necessária das propostas pedagógicas de seus cursos, bem como sistemas de apoio aos estudantes.

\section{Método}

\section{Participantes}

Participaram do estudo 339 estudantes de uma universidade pública na região Centro-Oeste do país, matriculados regularmente no 1 o ou $2 \mathrm{o}$ semestre acadêmico em um dos seguintes cursos: Ciências da Computação (9,1\%), Engenharia Ambiental (6,5\%), Engenharia Civil (7,7\%), Engenharia Mecânica (8,5\%), Engenharia Mecatrônica (5,3\%), Geologia (0,9\%), Matemática $(0,3 \%)$, Psicologia (7,5\%), Terapia Ocupacional $(0,3 \%)$, Administração (7,1\%), Ciências Naturais $(24,8 \%)$, Gestão Ambiental (7,5\%) e Gestão do Agronegócio (14,5\%). A idade média dos participantes foi de 19,8 anos $(D P=5,34)$. Dos 324 estudantes que informaram o sexo, 157 são homens e 167 mulheres. Cento e quarenta estudantes, de um total de 179 , informaram não trabalhar. Por uma falha na impressão do instrumento, na primeira aplicação não foram coletados dados relativos ao sexo e à situação de trabalho. Para as aplicações seguintes, o instrumento foi reimpresso, incluindo essas informações. Nesta pesquisa, utilizou-se uma amostra de conveniência.

\section{Instrumento e Procedimentos de Coleta e Análise dos Dados}

Foi utilizado, neste estudo, uma versão adaptada do Questionário de Percepções Acadêmicas - Versão A - Expectativas (QPA-E) (Almeida, Costa, et al., 2012), instrumento descrito na introdução deste artigo. Inicialmente, a redação do instrumento foi revista pelos autores deste estudo para adaptá-lo ao português do Brasil. Em seguida, solicitou-se a três pesquisadores portugueses que reescrevessem os itens da língua portuguesa do Brasil para a de Portugal. Observou-se correspondência entre os itens, considerando-se as duas 
versões da escala na língua portuguesa. Contudo, novos itens foram acrescidos ao instrumento para adequá-lo ao cenário brasileiro, em especial no que diz respeito às competências transversais, aspecto que vem sendo destacado nas diretrizes curriculares de diversos cursos de graduação, bem como nas políticas públicas para o Ensino Superior (Ministério da Educação, 2007, 2014). Essas competências pressupõem a integralidade das dimensões cognitivas, emocionais, afetivas, articuladas ao conhecimento teórico formal na formação de trajetórias profissionais cada vez mais complexas; englobando um conjunto diversificado de recursos pessoais, socioafetivos, princípios éticos e escolhas estéticas transversais às diferentes profissões e atividades profissionais (CabralCardoso, Estevão, \& Silva, 2006). Envolvem pensamento crítico, autonomia, criatividade, empreendedorismo, trabalho em equipe, organização, persistência, perseverança, flexibilidade, respeito à diversidade, responsabilidade social, entre outros.

Neste sentido, aos 42 itens originais da versão portuguesa do instrumento, foram integrados 20 novos itens à versão brasileira, totalizando 62 itens. Em seguida, realizou-se um estudo piloto para analisar semanticamente os itens adaptados e acrescentados, para garantir a sua compreensibilidade, evitando-se ambiguidade e formulações pouco apropriadas. Para tal, o instrumento foi aplicado em uma turma de estudantes matriculados em uma disciplina de graduação, e solicitou-se aos respondentes que indicassem possíveis itens confusos ou ambíguos e que sugerissem formulações para os mesmos. Cerca de 10 estudantes, que não integraram a amostra do presente estudo, responderam ao questionário. Na sequência, procedeu-se à reformulação de quatro itens do instrumento, substituindo-se palavras utilizadas no português de Portugal, porém pouco empregadas no português do Brasil, por palavras mais usadas no cotidiano brasileiro. Em seguida, foram convidados professores de alguns cursos, responsáveis por disciplinas ofertadas a alunos ingressantes na universidade, para lhes explicar os objetivos do estudo, obter sua colaboração e autorização e agendar um horário para aplicação dos questionários em suas turmas. Antes de responderem ao questionário, os participantes assinaram o Termo de Consentimento Livre e Esclarecido (TCLE). Vale ressaltar que o estudo foi aprovado por um comitê de ética em pesquisa.

Para estabelecer evidências de validade de construto do instrumento, foi examinada sua estrutura interna por meio de análise fatorial exploratória. Utilizando-se o pacote estatístico SPSS, foi realizada uma análise dos eixos (Principal Axis Factoring), com rotação oblíqua, antecedida por análise exploratória dos dados, visando a verificar a normalidade das distribuições e os pressupostos da análise fatorial. Estatística descritiva foi utilizada para análise das expectativas dos participantes do estudo.

\section{Resultados}

Com relação à fatorabilidade dos dados, o resultado do teste de adequação da amostra de Kaiser-Meyer-Olkin (KMO) foi 0,89, e o teste de esfericidade de Bartlett foi significativo, $\chi^{2}(1891)=10043,119, p<0,001$, indicando adequação dos dados à análise fatorial. Não foram encontrados mais do que $1,47 \%$ de casos omissos por variável, sendo eles excluídos da análise. Para verificar a fidedignidade dos fatores gerados, foi utilizado o coeficiente alfa de consistência interna. Na realização da análise fatorial, fixou-se a extração em sete fatores, respeitando o número de fatores avaliados pelo questionário em sua versão original. O item 26 ("Ao cursar o ensino superior, eu espero desenvolver as minhas características de personalidade") foi eliminado, pois não saturava suficientemente em nenhum dos fatores (0,30 como limiar dos índices de saturação aceitáveis). Os resultados obtidos indicam uma solução de sete fatores, utilizando-se o critério de Kaiser, que explica $42,75 \%$ da variância. A versão final da escala inclui, portanto, 61 itens.

O Fator 1, denominado Formação Acadêmica de Qualidade, inclui 12 itens relativos à obtenção de uma boa preparação para o exercício da profissão (ver Tabela 1). O eigenvalue desse fator foi 14,02, que explica $22,61 \%$ da variância comum. O índice de consistência interna foi de 0,82 . O Fator 2, intitulado Compromisso Social e Acadêmico, engloba 13 itens, relacionados à postura crítico-reflexiva diante de problemas sociais, objetivando a melhoria da qualidade de vida da sociedade (ver Tabela 2). O eigenvalue desse fator foi 3,31 , que explica $5,34 \%$ da variância comum. O índice de consistência interna foi de 0,90 . O Fator 3, denominado de Ampliação das Relações Interpessoais, inclui oito itens que contemplam a oportunidade de estabelecimento de novas redes de relacionamentos e a participação em atividades extracurriculares (ver Tabela 3). O eigenvalue desse fator foi 2,78 , que explica $4,49 \%$ da variância comum. $\mathrm{O}$ índice de consistência interna foi de 0,84 .

O Fator 4, intitulado Oportunidade de Internacionalização e Intercâmbio, conta com oito itens relativos à experiência e à ampliação da formação acadêmica em instituições estrangeiras (ver Tabela 4). O eigenvalue desse fator foi 2,58, que explica 4,16\% da variância comum. O índice de consistência interna foi de 0,87 .

O Fator 5, nomeado Perspectiva de Sucesso Profissional, engloba cinco itens relacionados à possibilidade de obtenção de um bom emprego que garanta estabilidade em uma profissão valorizada socialmente (ver Tabela 5). O eigenvalue desse fator foi 1,46, que explica $2,36 \%$ da variância comum. O índice de consistência interna foi de 0,71 . O Fator 6, intitulado Preocupação com a Autoimagem, inclui seis itens relacionados à necessidade de não fracassar e de corresponder às expectativas da família e amigos e do desejo de manter uma percepção 
positiva de si mesmo (ver Tabela 6). O eigenvalue desse fator foi 1,31 , que explica $2,11 \%$ da variância comum. $\mathrm{O}$ índice de consistência interna foi de 0,78. O Fator 7, denominado Desenvolvimento de Competências Transversais, inclui nove itens que dizem respeito ao desenvolvimento da capacidade de mobilização de recursos para lidar de forma eficaz com situações profissionais e pessoais inusitadas (ver Tabela 7). O eigenvalue desse fator foi 1,04 , que explica $1,68 \%$ da variância comum. O índice de consistência interna foi de 0,79 .

Tabela 1

Carga Fatorial e Correlação Item-Total dos Itens que Compõem o Fator 1

\begin{tabular}{|c|c|c|}
\hline Item & $\begin{array}{c}\text { Carga } \\
\text { fatorial }\end{array}$ & $\begin{array}{c}r \\
\text { item-total }\end{array}$ \\
\hline 7. Ter uma formação específica e atualizada na área do meu curso. & 0,37 & 0,36 \\
\hline 19. Ganhar confiança nas minhas potencialidades. & 0,42 & 0,49 \\
\hline 21. Ter um grupo de colegas interessados e envolvidos nas aulas e nas atividades de estudo. & 0,31 & 0,51 \\
\hline 22. Aprender a resolver problemas de forma criativa e inovadora. & 0,40 & 0,55 \\
\hline 36. Ter a preparação necessária para exercer a profissão que desejo. & 0,38 & 0,43 \\
\hline 47. Conseguir estágios que facilitem a entrada no mercado de trabalho. & 0,50 & 0,57 \\
\hline 49. Desenvolver uma perspectiva otimista do futuro. & 0,34 & 0,50 \\
\hline 50. Conseguir participar em projetos de pesquisa dos professores do meu curso. & 0,32 & 0,45 \\
\hline 53. Aprofundar conhecimentos na área do meu curso. & 0,46 & 0,55 \\
\hline 57. Obter uma boa formação acadêmica de acordo com os meus interesses. & 0,51 & 0,42 \\
\hline 59. Aproveitar a oportunidade que tenho para obter uma formação no ensino superior. & 0,47 & 0,49 \\
\hline 60. Ter professores competentes que me estimulem a aprofundar os conhecimentos do curso. & 0,33 & 0,49 \\
\hline
\end{tabular}

Tabela 2

Carga Fatorial e Correlação Item-Total dos Itens que Compõem o Fator 2

\begin{tabular}{|c|c|c|}
\hline Item & $\begin{array}{c}\text { Carga } \\
\text { fatorial }\end{array}$ & $\begin{array}{c}r \\
\text { item-total }\end{array}$ \\
\hline 3. Ter aulas que me desafiem a aprofundar conhecimentos. & 0,33 & 0,33 \\
\hline 11. Compreender como posso contribuir para melhorar o mundo e a sociedade. & 0,61 & 0,59 \\
\hline 14. Envolver-me na resolução de problemas de pessoas menos favorecidas socialmente. & 0,76 & 0,70 \\
\hline 15. Aprender a trabalhar em equipe. & 0,41 & 0,55 \\
\hline 17. Ter uma visão crítica do mundo e pensar em como transformá-lo. & 0,57 & 0,59 \\
\hline 23. Participar em atividades de voluntariado junto à comunidade. & 0,71 & 0,67 \\
\hline 32. Formar-me como um cidadão comprometido(a) com os problemas da sociedade atual. & 0,77 & 0,77 \\
\hline $\begin{array}{l}\text { 34. Participar de organização/representação dos estudantes no ensino superior (associações, } \\
\text { centros acadêmicos, etc.). }\end{array}$ & 0,43 & 0,52 \\
\hline 35. Aprofundar os conteúdos das disciplinas para participar ativamente nas aulas. & 0,44 & 0,50 \\
\hline 37. Participar em grupos de discussão sobre problemas sociais. & 0,78 & 0,75 \\
\hline 41. Poder discutir a vida política, econômica e social do país e do mundo. & 0,51 & 0,58 \\
\hline $\begin{array}{l}\text { 44. Participar em debates ou conferências científicas para aprofundar meus conhecimentos } \\
\text { no curso. }\end{array}$ & 0,49 & 0,55 \\
\hline 52. Contribuir para a melhoria da melhoria da condição humana ou bem-estar das pessoas. & 0,60 & 0,68 \\
\hline
\end{tabular}

A análise descritiva indicou que o Fator 5, Perspectiva de Sucesso Profissional $(M=5,54 ; D P=0,52)$, obteve a maior média, seguida do Fator 1, Formação Acadêmica de Qualidade $(M=5,32 ; D P=0,54)$, e do Fator 7, Desenvolvimento de Competências Transversais $(M=5,13 ; D P=0,65)$. Já o Fator 6 , Preocupação com a
Autoimagem, apresentou a média mais baixa $(M=4,06$; $D P=1,04)$. Ao se comparar as expectativas acadêmicas de homens e mulheres, observaram-se diferenças quanto ao Fator $2, t(163)=3,70 ; p<0,01$, ao Fator $5, t(163)=2,65$; $p=0,009$, e ao Fator 7, $t(161)=2,69 ; p=0,008$. As estudantes apresentaram médias superiores às dos estudantes 
nos três fatores. No Fator 2, a média das mulheres foi de $4,78(D P=0,70)$, e a dos homens foi de 4,34 $(D P=0,83)$.

No Fator 5, a média feminina foi de 5,61 $(D P=0,42)$, enquanto a masculina foi de $5,39(D P=0,62)$. No Fator 7 , as mulheres obtiveram média de $5,31(D P=0,55)$, e os homens, de 5,05 $(D P=0,69)$.

Tabela 3

Carga Fatorial e Correlação Item-Total dos Itens que Compõem o Fator 3

\begin{tabular}{lcc}
\multicolumn{1}{c}{ Item } & $\begin{array}{c}\text { Carga } \\
\text { fatorial }\end{array}$ & $\begin{array}{c}r \\
\text { item-total }\end{array}$ \\
\hline 2. Ter oportunidade de praticar alguma atividade extracurricular (esporte, cultura, lazer etc.). & 0,32 & 0,40 \\
6. Ter amigos que me ajudem a ultrapassar possíveis dificuldades pessoais. & 0,67 & 0,64 \\
12. Ter um horário semanal que me permita conviver mais com os colegas de curso. & 0,64 & 0,66 \\
27. Participar regularmente de festas com os colegas. & 0,54 & 0,55 \\
38. Ampliar a minha rede social de amigos. & 0,55 & 0,62 \\
48. Ter oportunidade para troca de experiências e conversas com colegas. & 0,31 & 0,53 \\
58. Ter momentos de convívio e diversão. & 0,58 & 0,66 \\
62. Conhecer e relacionar-me com pessoas diferentes. & 0,45 & 0,56 \\
\hline
\end{tabular}

Tabela 4

Carga Fatorial e Correlação Item-Total dos Itens que Compõem o Fator 4

\begin{tabular}{lcc}
\multicolumn{1}{c}{ Item } & $\begin{array}{c}\text { Carga } \\
\text { fatorial }\end{array}$ & $\begin{array}{c}r \\
\text { item-total }\end{array}$ \\
\hline 5. Sentir-me em uma Instituição de Ensino Superior que se esforça por se internacionalizar. & 0,30 & 0,46 \\
8. Participar em programas de intercâmbio estudantil universitário (Ciência sem fronteiras, & 0,64 & 0,64 \\
por exemplo). & 0,53 & 0,57 \\
13. Obter formação de qualidade internacional. & 0,82 & 0,73 \\
20. Conseguir realizar algum estágio em outro país. & 0,65 & 0,67 \\
25. Sentir que estou em uma Instituição de Ensino Superior que favorece o intercâmbio estudantil. & 0,66 & 0,60 \\
31. Obter formação que me permita alargar os horizontes de emprego no exterior. & 0,85 & 0,79 \\
40. Participar de intercâmbio estudantil passando algum tempo do curso em outro país. & 0,82 & 0,78 \\
55. Realizar estágios no exterior para obter reconhecimento internacional. & &
\end{tabular}

Tabela 5

Carga Fatorial e Correlação Item-Total dos Itens que Compõem o Fator 5

\begin{tabular}{lcc}
\multicolumn{1}{c}{ Item } & $\begin{array}{c}\text { Carga } \\
\text { fatorial }\end{array}$ & $\begin{array}{c}r \\
\text { item-total }\end{array}$ \\
\hline 1. Conseguir uma profissão valorizada socialmente. & 0,37 & 0,34 \\
10. Ter melhores opções profissionais no mercado de trabalho. & 0,66 & 0,55 \\
18. Obter formação para vir a ter um bom emprego. & 0,68 & 0,63 \\
24. Capacitar-me para ter sucesso profissional no futuro. & 0,43 & 0,40 \\
28. Aumentar a possibilidade de um emprego estável no futuro. & 0,50 & 0,44 \\
\hline
\end{tabular}

Tabela 6

Carga Fatorial e Correlação Item-Total dos Itens que Compõem o Fator 6

\begin{tabular}{lcc}
\multicolumn{1}{c}{ Item } & $\begin{array}{c}\text { Carga } \\
\text { fatorial }\end{array}$ & $\begin{array}{c}r \\
\text { item-total }\end{array}$ \\
\hline 9. Conseguir corresponder às expectativas dos meus familiares. & 0,44 & 0,49 \\
16. Participar em atividades de estudo para não ser excluído(a) pelos colegas. & 0,36 & 0,43 \\
29. Esforçar-me nos estudos para não me sentir inferiorizado(a) face aos meus colegas. & 0,64 & 0,59 \\
43. Não ficar atrás dos colegas nas notas ou menções. & 0,69 & 0,60 \\
46. Não desapontar a família ou os amigos no rendimento acadêmico. & 0,71 & 0,67 \\
61. Não atrasar a conclusão do curso para não aumentar os encargos financeiros da minha & 0,37 & 0,35 \\
formação. & & \\
\hline
\end{tabular}


Tabela 7

Carga Fatorial e Correlação Item-Total dos Itens que Compõem o Fator 7

\begin{tabular}{lcc}
\hline \multicolumn{1}{c}{ Item } & $\begin{array}{c}\text { Carga } \\
\text { fatorial }\end{array}$ & $\begin{array}{c}r \\
\text { item-total }\end{array}$ \\
\hline 4. Desenvolver uma atitude empreendedora (aproveitar oportunidades, assumir riscos etc.). & 0,39 & 0,30 \\
30. Aumentar a minha capacidade de reflexão e argumentação. & 0,34 \\
33. Ter objetivos na vida e saber "para onde quero ir". & 0,33 \\
39. Desenvolver competências de liderança. & 0,38 \\
42. Aprender a lidar autonomamente com as complexidades da vida. & 0,44 \\
45. Aprender a flexibilizar os meus pontos de vista. & 0,49 \\
51. Ter novas experiências de vida. & 0,41 \\
54. Adquirir competências para ser uma pessoa mais responsável e autônoma. & 0,50 \\
56. Desenvolver competências de comunicação (oral, escrita não verbal etc.). & 0,31 & 0,51 \\
\hline
\end{tabular}

\section{Discussão}

Na revisão de literatura realizada para essa pesquisa, observou-se que as expectativas em relação ao ingresso no Ensino Superior impactam a adaptação e o desempenho acadêmicos, bem como o desenvolvimento psicossocial dos estudantes (Almeida, 2007; Almeida \& Soares, 2003; Ferreira, Almeida, \& Soares, 2001; Soares et al., 2014). Os estudos mostram que, se o processo de transição e adaptação é bem sucedido no ingresso no Ensino Superior (geralmente no $1^{\circ}$ ano), a persistência e o sucesso dos alunos na sua trajetória formativa são fortemente evidenciados ao longo de sua vida acadêmica. Nesse processo de adaptação, as expectativas de entrada dos estudantes representam um dos importantes fatores para a integração ao Ensino Superior, bem como para o sucesso no enfrentamento das demandas acadêmicas, seu desenvolvimento pessoal e social. De acordo com Schleich (2006, p. 29), "o processo de integração ocorre na interação entre estudante e instituição e deve ser compreendido de maneira recíproca e dinâmica em que estudantes também são ativos na modificação do ambiente institucional". Assim, as expectativas dos estudantes podem incentivar, no interior das IES, políticas e procedimentos multidimensionais facilitadores do desenvolvimento dos jovens em relação a si próprios e também em relação aos objetivos institucionais propostos.

Os resultados obtidos nesta pesquisa sugerem que os estudantes ingressantes nos cursos de graduação da universidade pesquisada têm expectativas por uma formação de qualidade que os leve ao sucesso profissional; mas também esperam que o ingresso no Ensino Superior favoreça e potencialize seu desenvolvimento pessoal. Os achados levam-nos a hipotetizar ainda que a essas expectativas dos estudantes aliam-se, em uma perspectiva inovadora, desejos de aproveitar a oportunidade da formação no Ensino Superior para aprender a resolver problemas de forma criativa e inovadora, tornando-se uma pessoa mais responsável e autônoma diante das complexidades da vida, com maior capacidade de reflexão e argumentação, para aprender a flexibilizar pontos de vista e para desenvolver uma perspectiva otimista do futuro, atitudes empreendedoras e competências de liderança e comunicação. Essa interdependência entre características de desenvolvimento pessoal e profissional, contingências e contextos, apontada nos resultados da presente pesquisa, sinaliza para a formação de um perfil profissional ampliado. As competências técnicas aliam-se a inúmeras outras competências transversais, entendidas como um conjunto diversificado de recursos individuais e socioculturais, mobilizados com intencionalidade pelos sujeitos em situação de formação ou exercício profissional (Cabral-Cardoso et al., 2006; Le Boterf, 2003; MarinhoAraujo, 2009; Zarifian, 2001).

Os procedimentos adotados com a adaptação dos itens da versão portuguesa do QPA-E para a versão brasileira permitiram-nos estabelecer um paralelo entre as dimensões presentes nas duas escalas. Seis fatores se mantiveram em ambas as versões do instrumento e dizem respeito à qualidade na formação, sucesso profissional, intercâmbio internacional, compromisso social, interação social e preocupação em corresponder a expectativas familiares e sociais. Vale ressaltar que as dimensões Desenvolvimento Pessoal e Social (versão portuguesa) e Competências Transversais (versão brasileira) incorporam itens que estão, teoricamente, próximos - desenvolvimento de autonomia, autoconfiança, competências de comunicação etc. Os índices de consistência interna dos itens em cada dimensão foram satisfatórios (todos acima de 0,70$)$. Desse modo, os resultados indicam que a escala constitui ferramenta útil de avaliação das expectativas dos estudantes que ingressam nas IES, captando a natureza multidimensional dessas expectativas.

Considerando que o ingresso na universidade envolve uma série de mudanças pessoais, espera-se que o entendimento das expectativas dos ingressantes ajude a compreender as dificuldades encontradas por muitos estudantes no processo de integração e adaptação. Ademais, os dados poderão auxiliar no esclarecimento das razões que ocasionam as altas taxas de evasão das 
IES brasileiras, oferecendo informações complementares sobre esse fenômeno e contribuindo para a elaboração de propostas, programas ou sistemas de apoio aos estudantes e às instituições. Assim, as IES podem atualizar os cursos de graduação, o processo de ensino-aprendizagem, as metodologias e os sistemas de informação e de apoio levando em consideração o que os alunos estão buscando ao ingressarem nessa etapa de escolaridade. Diante dos desafios do mundo contemporâneo, as instituições acadêmicas devem promover condições para o desenvolvimento integral dos estudantes e de suas potencialidades visando à sua responsável preparação para atuar de forma cidadã na sociedade. Para finalizar, aponta-se que a pesquisa realizada, ainda que tenha apresentado algumas limitações relativas à amostra estudada, justificando a continuidade deste estudo, apresenta relevantes resultados que podem auxiliar na compreensão sobre o processo de adaptação do estudante ao Ensino Superior. A proporção entre o número de participantes por item foi de aproximadamente 5,50 , podendo ser considerada aceitável, mas não desejável. Nesse sentido, pretende-se avançar com novas pesquisas para validação dimensional da escala, ampliando o número de alunos da amostra e sua diversidade em termos dos cursos representados, explorando de modo mais aprofundado os aspectos envolvidos na adaptação ao Ensino Superior aqui evidenciados, a fim de ampliar seu potencial de aplicação em intervenções a serem promovidas no contexto das IES, bem como subsidiar ações e políticas educacionais de órgãos governamentais.

\section{Referências}

Almeida, L. S. (2007). Transição, adaptação académica e êxito escolar no ensino superior. Revista Galego-Portuguesa de Psicoloxía e Educación, 14(1), 203-215.

Almeida, L. S., \& Soares, A. P. (2003). Os estudantes universitários: sucesso escolar e desenvolvimento psicossocial. Em E. Mercuri \& S. A. J. Polydoro (Eds.), Estudante universitário: características e experiências de formação (pp. 15-40). Taubaté: Cabral.

Almeida, L. S., Guisande, M. A., \& Paisana, J. (2012). Participación extracurricular, ajuste y rendimiento académico en la enseñanza superior: un estudio con estudiantes portugueses. Anales de Psicologia, 28(3), 860-865.

Almeida, L., Costa, A. R., Alves, F., Gonçalves, P., \& Araújo, A. M. (2012). Expectativas acadêmicas dos alunos do ensino superior: construção e validação de uma escala de avaliação. Psicologia, Educação e Cultura, 16(1), 70-85.

Almeida, L., Marinho-Araujo, C. M., Amaral, A., \& Dias, D. (2012). Democratização do acesso e do sucesso no ensino superior: uma reflexão a partir das realidades de Portugal e do Brasil. Avaliação,17(3), 899-920.

Alves, F., Gonçalves, P., \& Almeida, L. S. (2012). Acesso e sucesso no ensino superior: inventariando as expectativas dos estudantes. Revista Galego-Portuguesa de Psicoloxía e Educación, 20(1), 121-131.

Araújo, A. M., Costa, A., Gonçalves, P., Almeida, L. S., Deaño, M., \& Gil, S. A. (2012, Julho). Expectativas académicas no primeiro ano do ensino superior: validação de uma escala de avaliação para a população portuguesa e espanhola. Trabalho apresentado no II Seminário Internacional Contributos da Psicologia a Educação. Braga, Portugal.

Astin, A. (1984). Student involvement: A developmental theory for higher education. Journal of College Student Personnel, 25(4), $297-308$.

Baker, R. W., \& Schultz, K. L. (1992). Measuring expectations about college adjustment. National Academic Advising Association Journal, 12(2), 23-32.

Cabral-Cardoso, C., Estêvão, C. V., \& Silva, P. (2006). Competências transversais dos diplomados do ensino superior-Perspectiva dos empregadores e diplomados. Guimarães: Tecminho.

Costa, A. R., Araújo, A. M., Gonçalves, P., \& Almeida, L. (2013). Expectativas académicas em alunos tradicionais e não-tradicionais de engenharia. Revista de Peruana de Psicología y Trabajo Social, 2(1), 63-74.

Crisp, G., Palmery, E., Turnbull, D., Nettelbeck, T., Ward, L., Le Couteur, ... Schneider, L. (2009). First year student expectations: Results from a university-wide student survey. Journal of University Teaching E Learning Practice, 6(1), 11-26.

Deano, M., Diniz, A. M., Almeida, L. S., Alfonso, S., Costa, A. R., Garcia-Señorán, M., ... Tellado-Gonzalez, F. (no prelo). Propiedades psicométricas del Cuestionário de Perceppciones Académicas para la evaluacion de las expectativas de los estudiantes de primer año en Ensenanza Superior. Anales de Psicologia.

Dias Sobrinho, J. (2010). Democratização, qualidade e crise da educação superior: faces da exclusão e limites da inclusão. Educação e Sociedade, 31(113), 1223-1245.

Dias Sobrinho, J. (2013). Educação superior: bem público, equidade e democratização. Avaliação, 18(1), 107-126.

Dourado, L. F. (2011). Políticas e gestão da educação superior no Brasil: múltiplas regulações e controle. Revista Brasileira de Política e Administração da Educação, 27(1), 53-65.

Fernandes, E. P., \& Almeida, L. (2005). Expectativas e vivências acadêmicas: impacto no rendimento acadêmico dos alunos do $1^{\circ}$ ano. Psychologica, 40(3), 267-278.

Ferreira, J. A., Almeida, L. A., \& Soares, A. P. (2001). Adaptação académica em estudante do $1^{\circ}$ ano: diferenças de género, situação de estudante e curso. Psico-USF, 6(1), 1-10.

Gil, S. A., Deaño, M. D., Rodríguez, A. C., Costa, A. R., Araújo, A., \& Almeida, L. (2013). Perfiles de expectativas académicas en alumnos españoles y portugueses de enseñansa superior. Revista Galego-Portuguesa de Psicoloxía e Educacional, 21(1), 125-136.

Gomes, G., \& Soares, A. B. (2013). Inteligência, habilidades sociais e expectativas acadêmicas no desempenho de estudantes universitários. Psicologia: Reflexão e Crítica, 26(4), 780-789.

Gonyea, R. M., Kish, K. A., Kuh, G. D., Muthiah, R. N., \& Thomas, A. D. (2003). CSEQ. Norms for the 4th edition. Bloomington, IN: Indiana University. 
Instituto Nacional de Estudos e Pesquisas Educacionais [INEP] (2014). Censo da educação superior: 2013. Brasília: INEP.

Jansen, E. P., \& van der Meer, J. (2007, Julho). First-year students' expectations and perceptions of readiness before they start university. Trabalho apresentado no 30th HERDSA Annual Conference, Adelaide, Austrália.

Jansen, E. P., André, S., \& Suhre, C. (2013). Readiness and expectations questionnaire: A cross-cultural measurement instrument for firstyear university students. Educational Assessment, Evaluation, and Accountability, 25(2), 115-130.

Kuh, G. D., \& Pace, C. R. (1998). College student expectations questionnaire. Bloomington: Center for Postsecondary Research and Planning, Indiana University.

Kuh, G. D., Gonyea, R. M., \& Williams, J. M. (2005). What students expect from college and what they get. Em T. Miller, B. Bender \& J. Schuh (Eds.), Promoting reasonable expectations: Aligning student and institutional thinking about the college experience (pp. 34-64). San Francisco: Jossey-Bass/National Association of Student Personnel Administrators.

Le Boterf, G. (2003). Desenvolvendo a competência dos profissionais. Porto Alegre: Artmed.

Lima, P. G. (2013). Políticas de educação superior no Brasil na primeira década do século XXI: alguns cenários e leituras. Avaliação, 18(1), 85-105.

Marinho-Araujo, C. M. (2009). Psicologia escolar na educação superior: novos cenários de intervenção e pesquisa. Em C. M. MarinhoAraujo (Ed.), Psicologia escolar. Novos cenários e contextos de pesquisa, formação e prática (pp. 155-202). Campinas: Alínea.

Ministério da Educação (2007). Portaria Normativa no 40 de 12 de dezembro de 2007. Brasília: Ministério da Educação.

Ministério da Educação (2014). Portaria Normativa no 08 de 14 de março de 2014. Brasília: Ministério da Educação.

Schleich, A. L. R. (2006). Integração na educação superior e satisfação acadêmica de estudantes ingressantes e concluintes (Dissertação de mestrado não publicada). Universidade Estadual de Campinas, Campinas, Brasil.

Smith, J. S., \& Wertlieb, E. C. (2005). Do first-year college students' expectations align with their first-year experiences? Journal of Student Affairs Research and Practice, 42(2), 153-174.

Soares, A. B., Francischetto, V., Dutra, B. M., Miranda, J. M., Nogueira, C. C. C., Leme, V., ... Almeida, L. S. (2014). O impacto das expectativas na adaptação acadêmica dos estudantes do ensino superior. Psico-USF, 19(1), 49-60.

Soares, A. P., \& Almeida, L. S. (2001, Setembro). Transição para a universidade: apresentação e validação do Questionário de Expectativas Académicas (QEA). Trabalho apresentado no VI Congresso Galaico-Português de Psicopedagogia. Braga, Portugal.

Vargas, H. M., \& Paula, M. F. C. (2013). Inclusão do estudante-trabalhador e do trabalhador-estudante na educação superior: desafio público a ser enfrentado. Avaliação, 18(2), 459-485.

Zarifian, P. (2001). Objetivo competência: por uma nova lógica. São Paulo: Atlas.

\section{Sobre os autores}

Claisy Maria Marinho-Araujo é Psicóloga com mestrado e doutorado em Psicologia pela Universidade de Brasília. Professora e pesquisadora do Instituto de Psicologia e do Programa de Pós Graduação em Processos de Desenvolvimento Humano e Saúde da Universidade de Brasília.

Denise de Souza Fleith possui graduação e mestrado em Psicologia pela Universidade de Brasília, doutorado em Psicologia Educacional pela University of Connecticut. Atualmente é professora associada do Departamento de Psicologia Escolar e do Desenvolvimento do Instituto de Psicologia da Universidade de Brasília.

Leandro Silva Almeida possui doutorado em Psicologia pela Universidade do Porto. No presente, é Professor Catedrático da Universidade do Minho.

Cynthia Bisinoto é Doutora pela Universidade de Brasília, com doutorado sanduíche na Universidade do Minho, Portugal. Atualmente é Professora Adjunto da Faculdade UnB Planaltina, na Universidade de Brasília.

Mauro Luiz Rabelo possui graduação, mestrado e doutorado em Matemática pela Universidade de Brasília. Atualmente é professor associado da Universidade de Brasília e decano (pró-reitor) de ensino de graduação. 